\title{
Determination of the Minimal Sequence Required for Antifreeze Activity of Type I Antifreeze Protein (AFP 37)
}

\author{
Kyoung Sun Park, ${ }^{\dagger, *}$ Woong Sic Jung, ${ }^{\dagger}$ Hak Jun Kim, ${ }^{\dagger, * * *}$ and Song Yub Shin ${ }^{\S, *}$ \\ ${ }^{\dagger}$ Division of Polar Life Sciences, Korea Polar Research Institute, Incheon 406-840, Korea \\ ${ }^{\ddagger}$ Department of Polar Sciences, University of Science and Technology, Incheon 406-840, Korea. ${ }^{*}$ E-mail: hjkim@kopri.re.kr \\ ${ }^{\S}$ Department of Cellular \& Molecular Medicine, School of Medicine, Chosun University, Gwangju 501-759, Korea \\ *E-mail:syshin@chosun.ac.kr \\ Received September 9, 2010, Accepted October 6, 2010
}

Key Words: Antifreeze activity, Thermal hysteresis, Type I antifreeze protein (AFP 37)

Five structurally different types of antifreeze proteins (AFPs) have been found in fish: the antifreeze glycoproteins and four protein types, I, II, III and IV. ${ }^{1-4}$ AFPs have in common the ability to lower the freezing point of blood serum, thus allowing fish to survive in subzero ocean temperatures. The type I AFPs, present in the blood of winter flounder, yellowtail flounder, Alaskan plaice and the shorthorn and grubby sculpin are the most widely studied class of fish AFPs. ${ }^{1}$ The most well-studied type I AFP is AFP37 isolated from the winter flounder, Pseudopleuronectes americanus. AFP 37 has 37 amino acids arranged in three complete 11-residue repeats Thr- $\mathrm{X}_{2}-\mathrm{Asx}-\mathrm{X}_{7}$, where Asx is Asp or Asn, and X is generally Ala or another amino acid that favors $\alpha$-helix formation. ${ }^{5}$ NMR study revealed that AFP 37 adopts an $\alpha$-helical structure with cap structure at the carboxy termini. ${ }^{6}$ Analysis of the X-ray structure and ice-binding properties led to the hypothesis that AFP 37 binds to a specific plane of ice through hydrogen bonds from the threonyl hydroxyl (Thr-2, Thr-13, Thr-24, and Thr-35). ${ }^{7,8}$ Furthermore, the mutation of the Thr residues to Ser, Val, Ala and allo-Thr have indicated that the hydrophobicity provided by the $\gamma$-methyl group of $\mathrm{Thr}$, in addition to hydrogen bonding involving other residues, is a key factor related to the ability to inhibit ice growth. ${ }^{9}$ In particular, the central two Thr residues (Thr-13 and Thr-24) of AFP 37 play key roles in the ice-binding property. ${ }^{9}$

Until now, a point mutation and N-terminal truncation of AFP 37 had been studied. ${ }^{4,-12}$ However, the studies on the truncated peptides with stepwise deletion from $\mathrm{N}$ - and $\mathrm{C}$-terminus of AFP
37 had not yet been performed. Therefore, in this study, in order to elucidate the minimal sequence required for antifreeze activity of AFP 37, we synthesized a series of $\mathrm{N}$ - and $\mathrm{C}$-terminal truncated peptides of AFP 37 with the central two Thr residues (Thr-13 and Thr-24) (Table 1). These truncated peptides (AFP 34, AFP 32, AFP 30, AFP 28, AFP 26, AFP 24, AFP 22 and AFP 20) were synthesized by a stepwise deletion of one residue or two residues from $\mathrm{N}$ - and C-terminus of AFP 37.

Table 2 summarizes the thermal hysteresis values obtained with a series of truncated peptides of AFP 37. AFP 37, AFP 34, AFP 32, AFP 30 and AFP 28 show a linear dependence of the antifreeze activity on the concentrations of the peptides. AFP 34, AFP 32, AFP 30 and AFP 28 preserved 99.1\%, 62.6\%,

Table 2. Thermal hysteresis (TH) values of the peptides at various concentrations

\begin{tabular}{cccccc}
\hline \multirow{2}{*}{$\begin{array}{c}\text { Peptide } \\
\text { concentration } \\
(\mathrm{mg} / \mathrm{mL})\end{array}$} & \multicolumn{5}{c}{ Thermal hysteresis $(\mathrm{TH})$ values $\left({ }^{\circ} \mathrm{C}\right)$} \\
\cline { 2 - 6 } & AFP 37 & AFP 34 & AFP 32 & AFP 30 & AFP 28 \\
\hline 40 & 1.07 & 1.06 & 0.67 & 0.60 & 0.17 \\
20 & 0.71 & 0.54 & 0.33 & 0.60 & 0.13 \\
10 & 0.56 & 0.51 & 0.32 & 0.26 & 0.08 \\
5 & 0.52 & 0.39 & 0.31 & 0.17 & 0.08 \\
2.5 & 0.32 & 0.16 & 0.14 & 0.14 & 0.06 \\
1.25 & 0.19 & 0.09 & 0.11 & 0.11 & 0.04 \\
0.63 & 0.07 & 0.04 & 0.04 & 0.03 & 0.03 \\
\hline
\end{tabular}

Table 1. Amino acid sequences and calculated and observed molecular masses of Type 1 AFP (AFP 37) and truncated peptides

\begin{tabular}{|c|c|c|c|}
\hline \multirow{2}{*}{ Peptides } & \multirow{2}{*}{ Amino acid sequences } & \multicolumn{2}{|c|}{ Molecular mass } \\
\hline & & Calculated & Measured $^{a}$ \\
\hline AFP 37 (Type 1 AFP) & DTASDAAAAAALTAANAKAAAELTAANAAAAAAATAR & 3242.5 & 3242.8 \\
\hline AFP 34 & TASDAAAAAALTAANAKAAAELTAANAAAAAAAT & 2900.1 & 2899.6 \\
\hline AFP 32 & ASDAAAAAALTAANAKAAAELTAANAAAAAAA & 2697.9 & 2698.5 \\
\hline AFP 30 & SDAAAAAALTAANAKAAAELTAANAAAAAA & 2555.7 & 2555.7 \\
\hline AFP 28 & DAAAAAALTAANAKAAAELTAANAAAAA & 2397.6 & 2397.5 \\
\hline AFP 26 & AAAAAALTAANAKAAAELTAANAAAA & 2211.4 & 2211.4 \\
\hline AFP 24 & AAAAALTAANAKAAAELTAANAAA & 2069.3 & 2069.3 \\
\hline AFP 22 & AAAALTAANAKAAAELTAANAA & 1927.1 & 1927.5 \\
\hline AFP 20 & AAALTAANAKAAAELTAANA & 1784.9 & 1785.5 \\
\hline
\end{tabular}

${ }^{a}$ Molecular masses were determined by MALDI-TOF MS. 


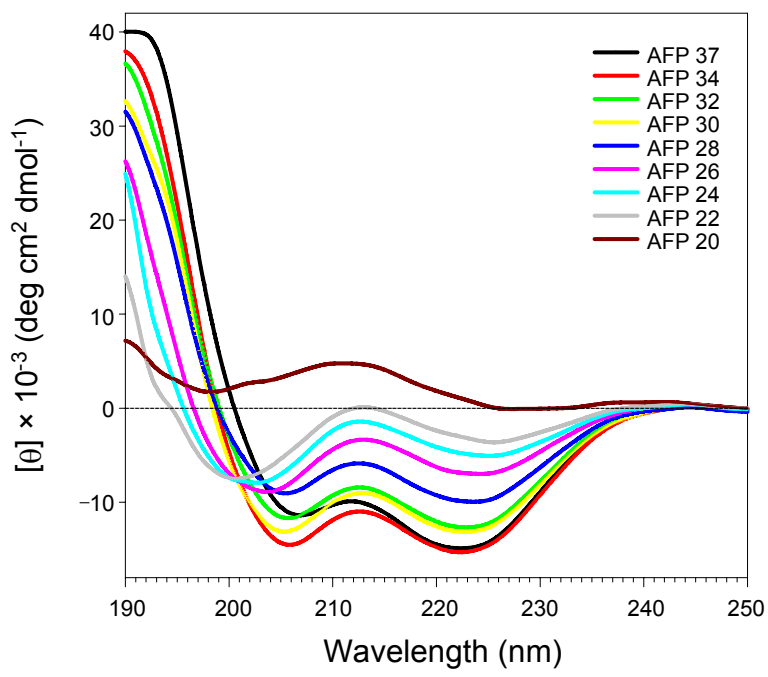

Figure 1. CD spectra of AFP 37 and truncated peptides in $0.1 \mathrm{M}$ $\mathrm{NH}_{4} \mathrm{HCO}_{3}(\mathrm{pH} 8.5)$.

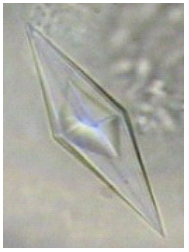

(a)

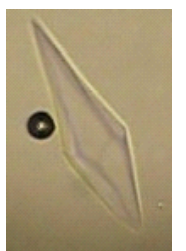

(d)

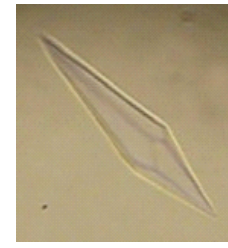

(b)

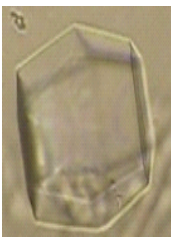

(e)

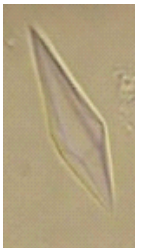

(c)

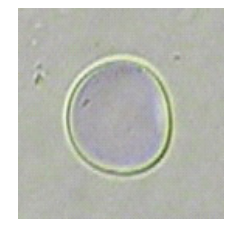

(f)
Figure 2. Video microscopy of ice crystals in the presence of AFP 37 and truncated peptides. Ice crystals were formed in the presence of $40 \mathrm{mg} / \mathrm{mL}$ peptide in $0.1 \mathrm{M} \mathrm{NH}_{4} \mathrm{HCO}_{3}(\mathrm{pH} 8.5)$ with an under cooling of $0.1^{\circ} \mathrm{C}$. (a) AFP 37, (b) AFP 34, (c) AFP 32, (d) AFP 30, (e) AFP 28, (f) other peptides (AFP 26, AFP 24, AFP 22 and AFP 20).

$56.16 \%$ and $15.9 \%$ thermal hysteresis activity of the wild type AFP (AFP 37) at a peptide concentration of $40 \mathrm{mg} / \mathrm{mL}$, respectively. However, a significant hysteresis was not observed with any of the AFP 26, AFP24, AFP22 and AFP 20 at $40 \mathrm{mg} /$ $\mathrm{mL}$ (data not shown). These results suggested that the minimal sequence required for antifreeze activity is from residue 5 to residue 32 of AFP 37 (AFP 28).

The influence of AFP 37 and truncated peptides on ice crystal morphology was monitored during thermal hysteresis measurements by video-microscopy (Fig. 2). In the presence of AFP 37, AFP 34, AFP 32, and AFP 30, the distinct ice crystalline hexagonal bipyramid at $40 \mathrm{mg} / \mathrm{mL}$ was observed, showing their strong binding preference for bipyramid plane of ice crystal. However, a hexagonal-shaped crystal was observed in the presence of AFP 28, showing less tighter binding to ice. The other shorter truncated peptides containing AFP 26, AFP 24, AFP 22
Table 3. Mean residual ellipticity at $222 \mathrm{~nm}$ and $\% \alpha$-helical content of the peptides

\begin{tabular}{ccc}
\hline Peptides & {$[\theta]_{222}$} & \% helical content \\
\hline AFP 37 & $-14,889.8$ & 41.9 \\
AFP 34 & $-15,295.0$ & 43.2 \\
AFP 32 & $-12,616.7$ & 34.8 \\
AFP 30 & $-13,093.2$ & 36.3 \\
AFP 28 & $-9,819.8$ & 26.1 \\
AFP 26 & $-6,822.6$ & 16.7 \\
AFP 24 & $-4,701.1$ & 10.0 \\
AFP 22 & $-2,944.3$ & 4.5 \\
AFP 20 & $1,168.2$ & - \\
\hline
\end{tabular}

and AFP 20 had no influence on ice crystal morphology. Ice crystals formed in their presence grew as disks perpendicular to the c-axis as the solution was cooled, which is seen with solutions lacking AFPs, indicating that these short peptides abolished all interactions with the ice surface (Fig. 2).

Furthermore, to investigate the relationship between the $\alpha$-helicity and antifreeze activity of the peptides, we measured the circular dichroism (CD) spectra of the peptides. Except for AFP 20, all of peptides showed a typical $\alpha$-helical structure with two negative bands at $208 \mathrm{~nm}$ and $222 \mathrm{~nm}$ and a positive band at $195 \mathrm{~nm}$ (Fig. 1). Based on molar elipticity values, the $\alpha$-helical content of these peptides decreased with the decrease in peptide length and antifreeze activity (Table 3 ). These results suggested that $\alpha$-helicity of the peptides is important for antifreeze activity.

\section{Experimental Section}

Peptide synthesis. AFP 37 and its truncated peptides listed in Table 1 were prepared using the standard Fmoc-based solidphase synthesis technique on Fmoc-amino acid-Wang resin. DCC and HOBt were used as coupling reagents, and 10-fold excess of Fmoc-amino acids was added during every coupling cycle. Fmoc-protecting groups were removed using $20 \%$ piperidine in dimethylformamide (DMF). After synthesis, the peptides were cleaved from the resin and deprotected by treatment for $2 \mathrm{~h}$ with trifluoroacetic acid/ $\mathrm{H}_{2} \mathrm{O} /$ thioanisole/phenol/ethanedithiol/triisopropylsilane (81.5:5:5:5:2.5:1, v/v). The crude peptides were repeatedly extracted with diethyl ether and purified by reverse-phase high-performance liquid chromatography (RP-HPLC) on a Vydac $\mathrm{C}_{18}$ preparative column $(20 \mathrm{~mm} \times 250$ $\mathrm{mm}, 300 \AA$, 5 - $\mu \mathrm{m}$ particle size) using water acetonitrile gradients containing $0.05 \%$ trifluoroacetic acid in both mobile phases. The final purity of the peptides $(>98 \%)$ was assessed by RP-HPLC on an analytical Vydac $\mathrm{C}_{18}$ column $(4.6 \mathrm{~mm} \times$ $250 \mathrm{~mm}, 300 \AA, 5-\mu \mathrm{m}$ particle size). The molecular masses of the purified peptides were determined using matrix-assisted laser desorption/ionization time-of-flight mass spectrometry (MALDI-TOF MS) (Shimadzu, Japan) (Table 1).

Measurement of antifreeze activity. Antifreeze activity or thermal hysteresis (defined as the difference between the equilibrium melting and nonequilibrium freezing point of the solution) of synthetic peptides was measured as described previously. ${ }^{9,10,13}$ Measurements were made in $0.1 \mathrm{M}$ ammonium bicarbonate ( $\mathrm{pH}$ 8.5) using a nanoliter osmometer (Otago Osmo- 
meters, Dunedin, New Zealand) connected to a cold well stage mounted on an Olympus model CH-2 microscope stage equipped with a Canon Digital Camera. Ice crystal morphology changes were also observed and recorded using the same experimental setup. ${ }^{14}$ Briefly, about $1.5 \mu \mathrm{L}$ of peptide solution was layered into a nanolitre osmometer well and frozen rapidly below $-20^{\circ} \mathrm{C}$. The resulting multicrystalline ice was warmed up slowly until only one small ice crystal remained. The temperature was lowered again continuously at a cooling rate of $0.05{ }^{\circ} \mathrm{C} / \mathrm{min}$ while the ice crystal morphology was maintained. The freezing point of the solution was taken by the temperature at which the ice crystal burst. All TH values were measured in triplicate.

Circular dichroism (CD) spectroscopy. The circular dichroism (CD) spectra of the peptides were recorded at $25^{\circ} \mathrm{C}$ using a Jasco J-715 CD spectrophotometer (Tokyo, Japan). The samples were scanned at room temperature in a capped quartz cuvette (1-mm path length) cells in the wavelength range of $190-250$ $\mathrm{nm}$. The spectra were recorded at a peptide concentration of $100 \mu \mathrm{g} / \mathrm{mL}$ in $0.1 \mathrm{M}$ ammonium bicarbonate buffer ( $\mathrm{pH} 8.5$ ). The mean residue ellipticity, $[\theta]$, was given in $\mathrm{deg} \cdot \mathrm{cm}^{2} \cdot \mathrm{dmol}^{-1}$ : $[\theta]=[\theta]$ obs $(\mathrm{MRW} / 10 \times 1 \times \mathrm{c})$, where: $[\theta] \mathrm{obs}$ is the ellipticity measured in millidegrees, MRW is the mean residue molecular weight of the peptide, $\mathrm{c}$ is the concentration of the sample in $\mathrm{mg} / \mathrm{mL}$, and 1 is the optical path length of the cell in $\mathrm{cm}$. The spectra were expressed as molar ellipticity $[\theta] v s$. wavelength. The percent helical content of peptides in $\alpha$-helical structure was calculated as follows:

$$
\% \text { helical content }=\left(\theta-\theta_{\mathrm{RC}}\right) /\left(\theta_{\mathrm{H}}-\theta_{\mathrm{RC}}\right) \times 100
$$

where $\theta$ is observed ellipticity and $\theta_{\mathrm{RC}}$ and $\theta_{\mathrm{H}}$ are the limiting values for a completely random coil and a completely helical conformation, respectively. Here, we used the following values,

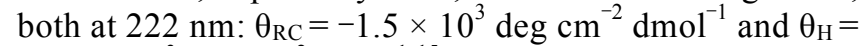

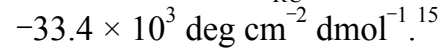

Acknowledgments. This work was supported by Korea Polar Research Institute Grant No. PE10070 and PG10010 (to HJK).

\section{References}

1. Davies, P. L.; Hew, C. L. FASEB J. 1990, 4, 2460.

2. Davies, P. L.; Sykes, B. D. Curr. Opin. Struct. Biol. 1997, 7, 828.

3. Harding, M. M.; Ward, L. G.; Haymet, A. D. Eur. J. Biochem. 1999, 264, 653.

4. Madura, J. D.; Baran, K.; Wierzbicki, A. J. Mol. Recognit. 2000, 13, 101.

5. Chakrabartty, A.; Ananthanarayanan, V. S.; Hew, C. L. J. Biol. Chem. 1989, 264, 11307.

6. Sönnichsen, F. D.; Davies, P. L.; Sykes, B. D. Biochem. Cell Biol. 1998, 76, 284.

7. Sicheri, F.; Yang, D. S. Nature 1995, 375, 427.

8. Yang, D. S. C.; Sax, M.; Chakrabartty, A.; Hew, C. L. Nature 1988, $333,232$.

9. Zhang, W.; Laursen, R. A. J. Biol. Chem. 1998, 273, 34806.

10. Chao, H.; Houston, M. E., Jr.; Hodges, R. S.; Kay, C. M.; Sykes, B. D.; Loewen, M. C.; Davies, P. L.; Sönnichsen, F. D. Biochemistry 1997, 36, 14652.

11. Liepinsh, E.; Otting, G.; Harding, M. M.; Ward, L. G.; Mackay, J. P.; Haymet, A. D. Eur. J. Biochem. 2002, 269, 1259.

12. Tomczaka, M. M.; Hincha, D. K.; Crowe, J. H.; Harding, M. M.; Haymet, A. D. FEBS Lett. 2003, 551, 13.

13. Chakrabartty, A.; Yang, D. S.; Hew, C. L. J. Biol. Chem. 1989, $264,11313$.

14. Wen, D.; Laursen, R. A. J. Biol. Chem. 1992, 267, 14102.

15. Ladokhin, A. S.; White, S. H. J. Mol. Biol. 1999, 285, 1363. 